Article

\title{
Enhancing the Accuracy of Advanced High Temperature Mechanical Testing through Thermography
}

\author{
Jonathan Jones
}

Institute of Structural Materials, Swansea University, Singleton Park, Sketty, Swansea SA2 8PP, UK; jonathan.p.jones@swansea.ac.uk; Tel.: +44-179-260-4379

Received: 6 November 2017; Accepted: 24 February 2018; Published: 6 March 2018

\begin{abstract}
This paper describes the advantages and enhanced accuracy thermography provides to high temperature mechanical testing. This technique is not only used to monitor, but also to control test specimen temperatures where the infra-red technique enables accurate non-invasive control of rapid thermal cycling for non-metallic materials. Isothermal and dynamic waveforms are employed over a $200-800{ }^{\circ} \mathrm{C}$ temperature range to pre-oxidised and coated specimens to assess the capability of the technique. This application shows thermography to be accurate to within $\pm 2{ }^{\circ} \mathrm{C}$ of thermocouples, a standardised measurement technique. This work demonstrates the superior visibility of test temperatures previously unobtainable by conventional thermocouples or even more modern pyrometers that thermography can deliver. As a result, the speed and accuracy of thermal profiling, thermal gradient measurements and cold/hot spot identification using the technique has increased significantly to the point where temperature can now be controlled by averaging over a specified area. The increased visibility of specimen temperatures has revealed additional unknown effects such as thermocouple shadowing, preferential crack tip heating within an induction coil, and, fundamental response time of individual measurement techniques which are investigated further.
\end{abstract}

Keywords: thermography; high temperature; dynamic temperature; thermocouple; pyrometer

\section{Introduction}

Uncertainty still remains with regards to how accurately temperature can be measured and controlled, especially in dynamic circumstances during mechanical testing. Significant momentum is building to establish a technique capable of delivering accurate control of complex high temperature waveforms, driven in some instances by the gas turbine sector. Unfortunately, the development of new alloys and component designs to further enhance performance and efficiency of the gas turbine engine is becoming increasingly complex, expensive and time consuming. In order to try and maintain the rapid development of gas turbine performance and efficiency existing in-service materials continue to be used and subjected to more extreme thermal environments. As a consequence, aggressive high temperature damage mechanisms such as thermo-mechanical fatigue (TMF), become more prevalent and therefore require further consideration in advanced component lifing strategies [1].

Fatigue life predictions based only on isothermal testing can potentially be non-conservative. TMF loading is often found to be more detrimental in terms of cyclic life than fatigue testing at a corresponding peak or minimum cycle temperature. Accurate temperature and mechanical loading control during these dynamic cycles is essential, as it enables the phasing between temperature and load, known as the phase angle, $\phi$, to be realised. Reliable results to be derived for component lifing interpretation would not be possible without accurate temperature control.

Since 2011, the publication of two strain controlled TMF standards [2,3], emphasises the significance of dynamic temperature effects on material fatigue behaviour and the necessity of accurate 
control. Previous work has highlighted its significance to deliver the required phasing between mechanical and thermal loading [4]. Deviations in phase angle of $\pm 10^{\circ}$ have shown to have clear effects on the cyclic deformation behaviour of metallic materials. As such it has been recommended to keep phase shifts to within $\pm 2^{\circ}$ of the target phase angle [2-4]. However, despite the standardisation of test methods such as TMF, uncertainty still remains with regards to how accurately temperature can be measured and controlled, especially in dynamic circumstances such as TMF. Previous studies have shown that temperature accuracy has a significant impact when considering data scatter [5-9].

Traditional isothermal heating methods comprise of a conventional resistance furnace, with temperature monitored by tie on thermocouples (TCs). The technique is not suitable for the rapid dynamic thermal cycling required by TMF as the heating and cooling rates generated by the furnace are too slow. Furthermore, the accuracy of tie on TCs under such rapid thermal cycling is not acceptable when used for dynamic temperature control and must be spot welded. To overcome the established impact of spot welding on the specimen gauge section upon crack initiation [10], spot welding TCs on the specimen shoulder for dynamic high temperature control has been recommended [2,3]. However, despite these recommendations, the accuracy and practicality of such a technique under rapid dynamic thermal cycles is questionable, particularly in specimens with a long parallel gauge section, where large distances exist between the material under investigation and the TC location on the test piece shoulder [11].

Understanding the dynamic temperature effects associated with TMF is particularly important in the aerospace sector. In order to achieve desirable temperature ramp rates to simulate engine flight cycles which may exceed $\pm 10^{\circ} \mathrm{C} / \mathrm{sec}$, radiant lamp furnaces (RLF) or induction coil systems (ICS) are typically employed [11,12]. A variety of temperature control options now exist for these heating systems with the predominant control methods being spot welded TCs, pyrometers and most recently a technique using an infra-red camera known as thermography $[11,13]$. However, the use of pyrometers or thermography for dynamic temperature control is not yet recommended by the relevant standards involved with cyclic high-temperature testing such as TMF [2,3].

Not only have infra-red techniques proven sensitive and accurate enough to control and monitor temperature, but have been employed to uncover valuable material effects. Infra-red has been used to characterise the dynamic properties of materials to thereby pre-determine their fatigue limit [14], and also used in the assessment and separation of the effects of elastoplasticity and thermoelasticity [15], are two examples. Thermography has also been a vital tool to aid investigations into quantifying the effects of frequency in ultrasonic or very high cycle fatigue (VHCF) testing upon temperature [16]. Such effects are not prevalent in the current work as typical dynamic temperature tests such as TMF are undertaken at low frequencies, characteristically $0.0333 \mathrm{~Hz}$ equivalent to a thirty second cycle at a maximum.

Infra-red techniques are sensitive to changes in the surface condition of the test specimen predominantly caused by progressive oxidation at high temperatures that in turn affects the surface emissivity and the accuracy of the technique [17]. Depending on the specific temperature and wavelength, the energy radiated by a metallic surface is highly sensitive to any change in the surface condition and therefore is directly proportional to the spectral emissivity of the object [5]. Without a stable emissivity value, it is extremely difficult to achieve accurate temperature measurement with a non-invasive technique such as a pyrometer [1,5,17-22]. Pyrometry does offer non-invasive temperature monitoring and control [23], however the measurement reading is limited to a particular location on the specimen, a limitation shared with TCs [24].

A solution to this issue is to pre-oxidize the specimen to produce a stable oxide layer and hence stable surface emissivity [1]. However, pre-heat treatments and thus consistent oxide formation has previously been found to lack repeatability where previous work has found that the surface emissivity evolution with temperature is dependent on the material, surface preparation, thermal treatment, and the chemical reactions on the surface [25]. Further work suggests that there is no conclusive trend of emissivity observed as a function of oxidation time $(15 \pm 60 \mathrm{~min})$ at a given oxidation temperature [26]. 
However, provided a stable oxide layer, and thus a constant surface emissivity can be achieved, the high-temperature pre-exposure and resultant oxide formation can influence the fatigue life of the test piece [27]. A reduction in fatigue life occurs for some alloys subjected to pre-test temperatures $\geq 500{ }^{\circ} \mathrm{C}$ with reductions in fatigue life resulting from surface oxide scale cracking in combination with increased crack growth rates from enhanced susceptibility to intergranular cracking [28,29]. This effect was investigated on two Ni-base superalloys in the temperature range $650-704{ }^{\circ} \mathrm{C}$ for exposures of 100 to $\geq 1000 \mathrm{~h}$ [28]. The investigation concluded that pre-exposure increased scatter in the results and reduced fatigue life by up to $70 \%$ compared to unexposed specimens.

An alternative to pre-oxidation is to paint the surface to achieve an adequate emissivity. The use of thermal paints (TP) to measure, correct, and reduce the influence of surface emissivity values have been described in previous work [30]. These paints can be applied to encompass the entire specimen surface as a permanent coating. Alternatively, the paint can be applied in a single smaller location or a small spot to determine the emissivity by comparing the measured radiance temperature of this spot with that of the uncoated surface [30]. To avoid complications and inaccuracies with respect to radiation from nearby heat sources, such TPs should yield as high an emissivity value as possible, close to the emissivity of a blackbody, which is rated with a value of 1 [8]. Rolls-Royce plc developed a variety of novel thermal indicating paints and high-emissivity thermal paints, for use with gas turbine engine development which display an array of permanent colour changes in proportion with the temperature they are exposed to, and typically encompass a temperature range of $140-1330^{\circ} \mathrm{C}[30,31]$. The emissivity of the HE23 TP was found to be stable over a wide temperature range up to $1300^{\circ} \mathrm{C}$ using pyrometers. This was maintained over a range of incidence angles as a result of its high stability and lower angular dependency on emissivity. Effectively, HE23 TP can deliver a constant, very high emissivity value across an extremely wide temperature range and has the potential to prove invaluable in delivering accurate temperature measurement over an extensive range of both high and low temperatures under non-invasive techniques [30].

In this paper, HE23 TP is used in combination with the thermography technique to demonstrate its stability, accuracy, and repeatability of temperature measurement and control in comparison to traditional spot welded TCs. This paper demonstrates the inaccuracy of traditional techniques in dynamic temperature testing using thermography. Furthermore, the use of thermography allows for comprehensive temperature visualisation. Unique TMF testing is undertaken upon a non-metallic ceramic composite material (CMC), using thermography for temperature control on a bespoke purpose built TMF system.

\section{Materials and Methods}

In this investigation various testing systems have been utilized comprising of both MTS $250 \mathrm{kN}$ Landmark servo-electric and servo-hydraulic load frames. Focusing on the heating and temperature control systems employed, these include IC, RLF, pyrometers, thermocouples and infra-red thermography cameras. The heating systems and their associated temperature control techniques investigated and compared in this investigation are listed in Table 1.

Table 1. Heating and temperature control techniques employed and compared within this investigation.

\begin{tabular}{cccc}
\hline ID & TMF Test Type & Heating System & Temperature Control Technique \\
\hline 1 & Strain Control & Non-Uniform multi-turn longitudinal field helical coil & Pyrometer \\
2 & Load Control & $12 \mathrm{~kW}$ Infra-red radiant lamp furnace & Non-contact thermocouple \\
3 & Crack Growth & Non-uniform multi-turn longitudinal field helical coil & Thermocouple \\
4 & Load Control & $12 \mathrm{~kW}$ Infra-red radiant lamp split furnace & Thermography \\
\hline
\end{tabular}

The $12 \mathrm{~kW}$ RLF comprises of two longitudinally divided half cylinders hinged at the centre, with each half containing six lamps. The 12 high-power, vertically mounted quartz lamps heat the 
specimen to the test temperature. Behind each lamp is a parabolic reflector, which focuses the radiant light toward the centre of the furnace. The infra-red camera was mounted on the front of the RLF, positioned to image the specimen through the extensometer portal, shown in Figure 1a.

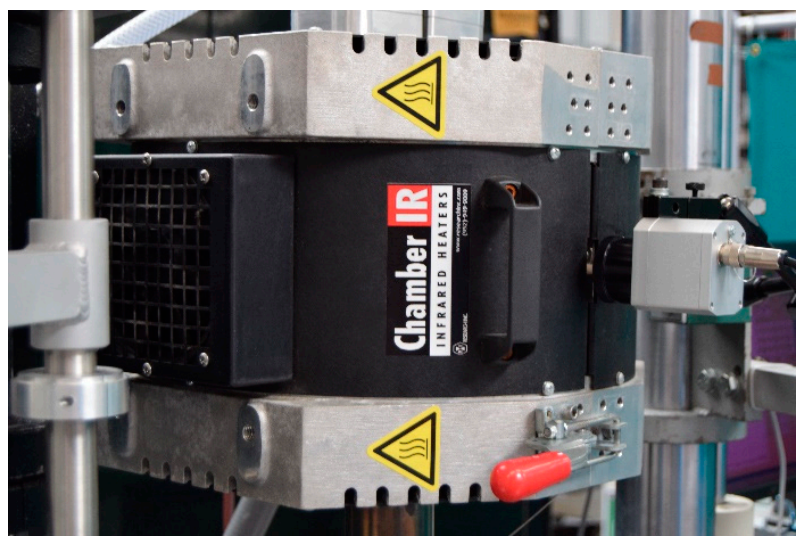

(a)

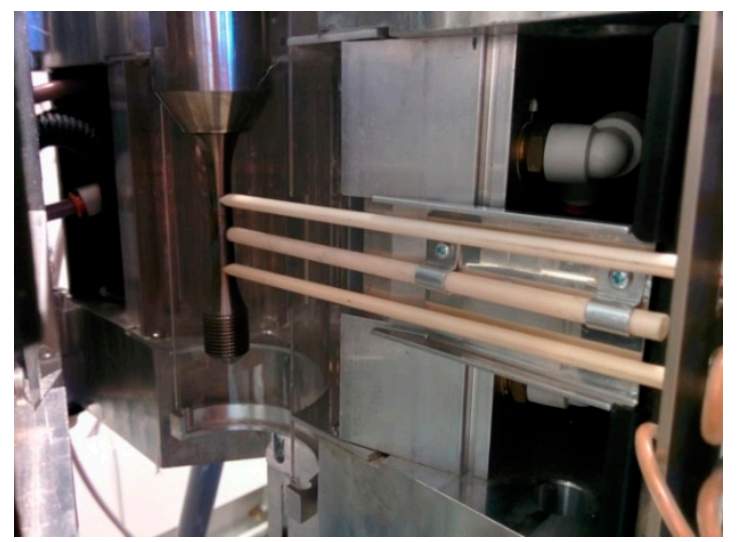

(b)

Figure 1. A 1st generation $12 \mathrm{~kW}$ vertically mounted quartz lamp infra-red radiant lamp furnace (a) Furnace overview with infra-red camera externally mounted, aimed at the test specimen through the extensometer furnace window; (b) Internal furnace view, displaying a side mounted extensometer between the arms the ceramic housing for the non-contact control thermocouple.

A second generation RLF furnace was designed in collaboration with Severn Thermal Solutions Ltd. with thermography temperature control at the forefront of the design specification. The $12 \mathrm{~kW}$ RLF is a standard split body design with each half containing three horizontally mounted lamps. The external surface of the RLF is coated black with araldite to avoid any reflective radiation complications with the infra-red thermography temperature control. Example images of the bespoke setup are given in Figure 2, with a schematic representation shown in Figure 3. The furnace has been specifically designed to accommodate both an extensometer and a non-invasive temperature measurement device, through two opposing furnace windows. Three independently controllable heating zones allow for accurate temperature control and profiling, whist built-in internal compressed air cooling delivers the rapid cooling rates required by the complex TMF waveforms.

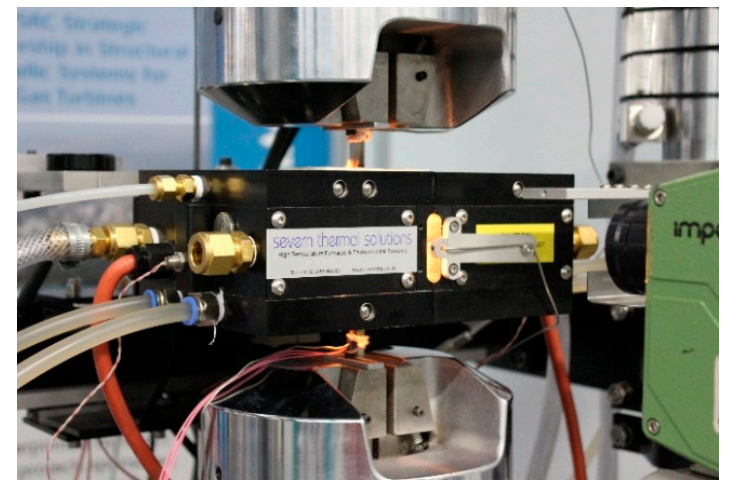

(a)

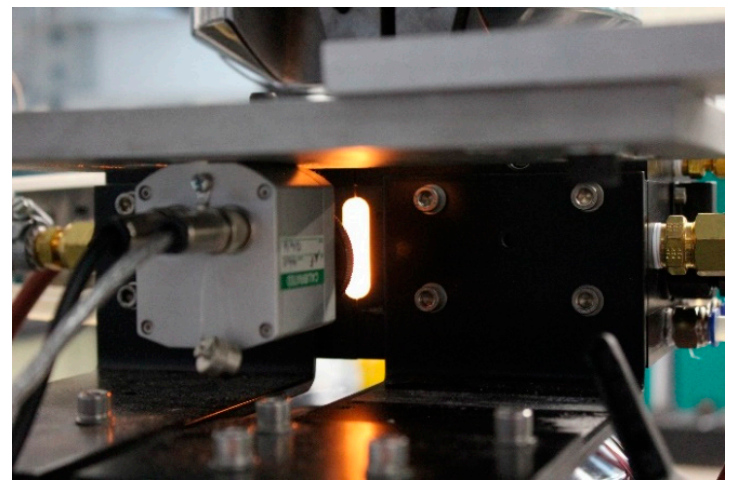

(b)

Figure 2. A 2nd generation $12 \mathrm{~kW}$ horizontally mounted quartz lamp infra-red radiant lamp furnace (a) Front view, displaying externally mounted pyrometer aimed the test specimen through a furnace window; (b) Rear view, the temperature controlling infra-red camera aimed at the test specimen through the rear furnace window is visible. 


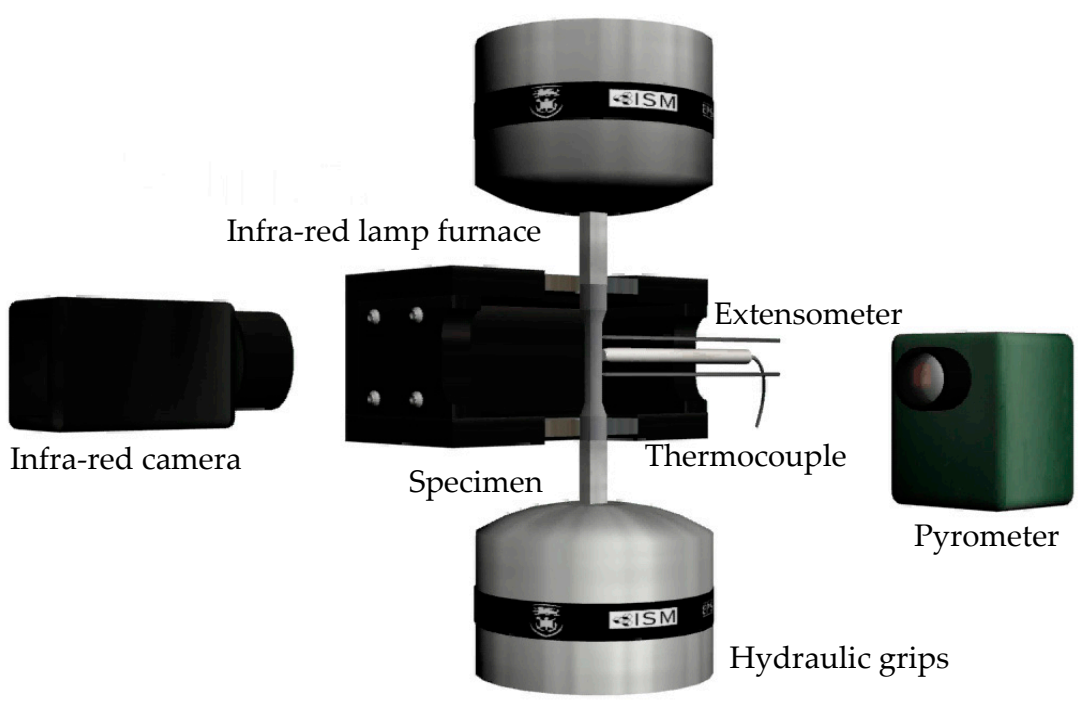

(a)

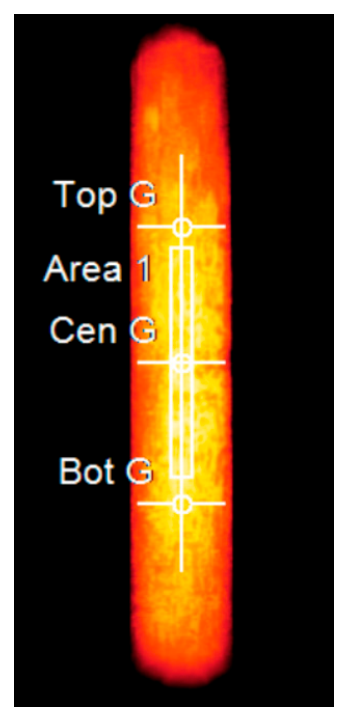

(b)

Figure 3. (a) Schematic representation of the bespoke thermo-mechanical fatigue test setup tailored specifically for non-metallic materials utilising thermography; (b) Example overview of thermography view of test specimen temperatures.

As previously mentioned, induction heating is an established method of providing rapid and reliable dynamic heating and as such in this investigation a Trueheat $10 \mathrm{~kW}$ induction coil (IC) heater is used to deliver an effective method of heating metallic specimens to temperatures up to $120{ }^{\circ} \mathrm{C}$. Peak temperatures and heating rates are dependent on the material, coil design and specimen geometries employed. Metallic materials were heated directly with tailored IC design, ensuring uniform heating over the entire gauge section of the test piece. Depending on the coil design used, this system enabled an infra-red camera to be mounted in various positions around the test piece to enable a $360^{\circ}$ view of both heating and cooling effects. Both transversal and longitudinal electromagnetic fields are employed. Example images of the ICS setups and thermographic views of the specimen are given in Figure 4.

Examples of different specimen geometries used to explore the flexibility of thermography are shown in Figure 5. HE23 TP was applied to some specimens to maintain a stable surface emissivity and different coating designs were employed for different applications, for example, for thermography control and complete gauge section temperature assessment the entire surface is coated, see Figure 5a. Specimens were coated leaving small areas of the specimen exposed to enable pyrometer or TC measurements upon oxidised surfaces, (Figure $5 \mathrm{~b}$ or coated to allow stable pyrometer control (Figure 5c). Polished and pre-oxidised metallic specimen surfaces were also assessed, as well as a non-metallic CMC. An example of complications residing from polished metallic surfaces is given in (Figure 5d), where a lack of adhesion between the TP and polished metallic surface results in spallation of the paint after thermal exposure. 


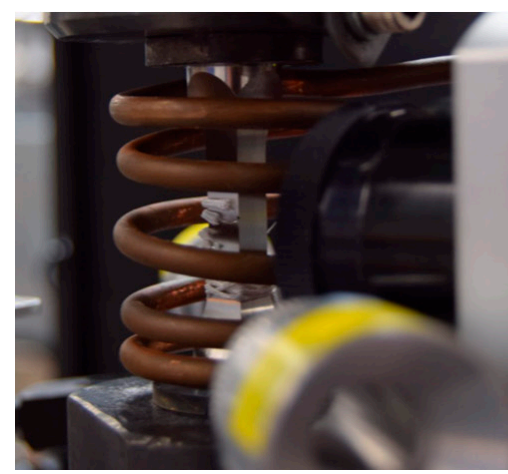

(a)

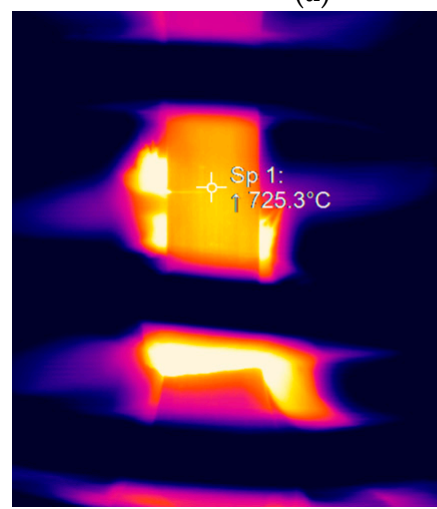

(c)

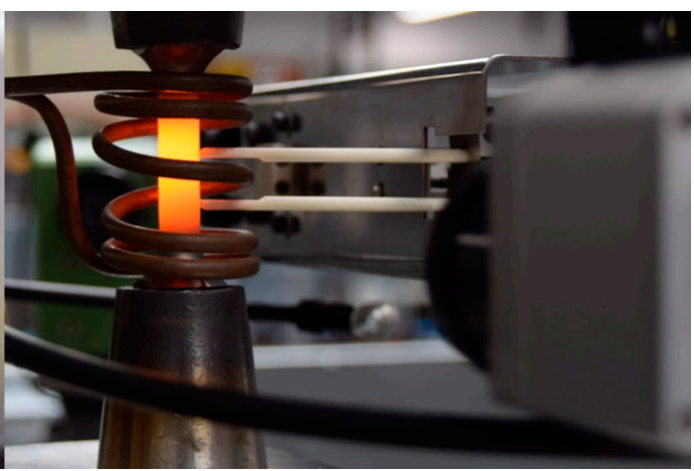

(b)

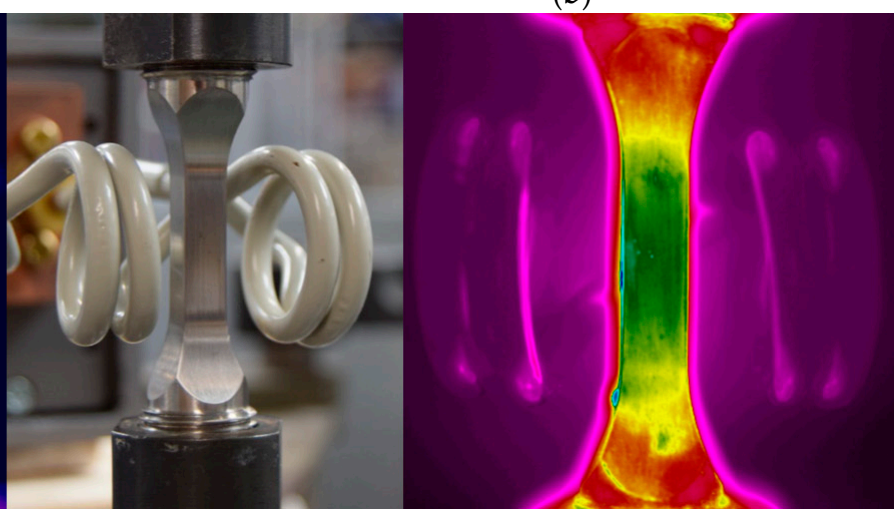

(d)

(e)

Figure 4. Example helical induction coil configurations used in this investigation; (a) Non-Uniform longitudinal field used for load control crack growth; (b) Non-Uniform longitudinal field used for extension control; (c) Thermography view of $7 \times 7 \mathrm{~mm}$ crack growth specimen in (a); (d) Split transversal electromagnetic field; (e) Thermography view of $7 \times 7 \mathrm{~mm}$ crack growth specimen in (d).

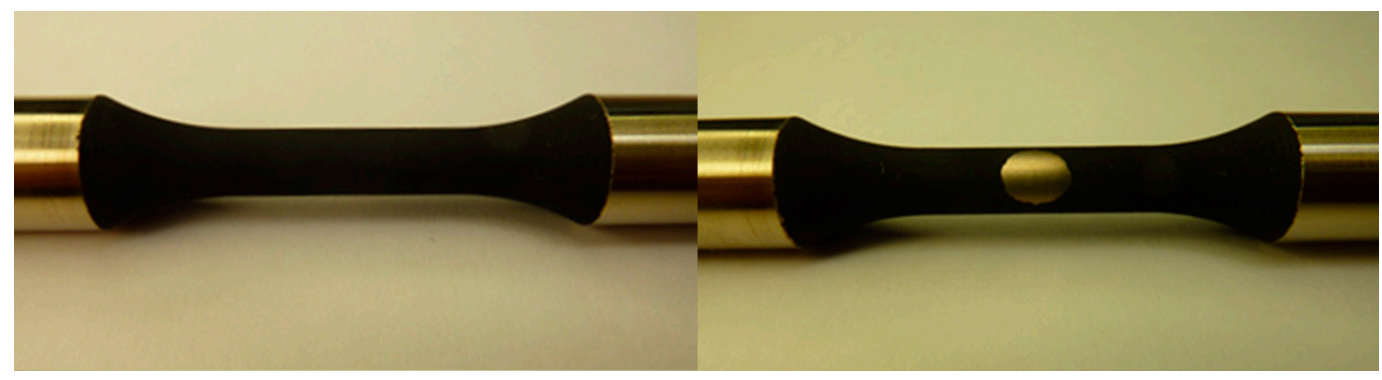

(a)

(b)

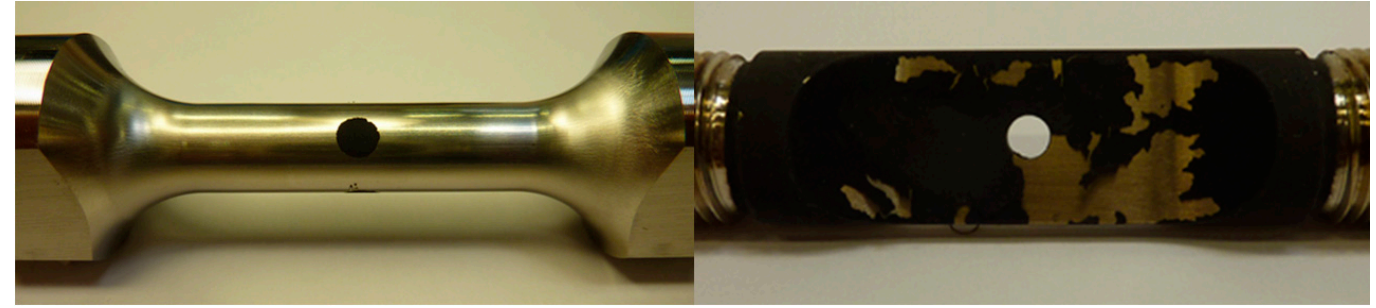

(c)

(d)

Figure 5. Test-piece geometries and HE23 thermal paint coating combination examples used in this investigation. (a) Cylindrical specimen with gauge section entirely coated with HE23; (b) Cylindrical specimen with gauge section coated in HE23 allowing for thermocouple attachment; (c) Hollow cylindrical specimen with circular HE23 coated area for pyrometer measurement; (d) Rectangular, feature specimen with HE23 thermal paint spalling from a polished metallic surface. 
To avoid further spallation complications, prior to coating with TP, the specimen surfaces were lightly grit blasted with 120/220 grit to slightly roughen the surface so to improve the bond between the specimen and the TP as described in previous work $[11,13,30]$. A conventional air spray gun was used to apply the paint to a thickness of approximately $20-25 \mu \mathrm{m}[11,13]$. The paint was then air dried and cured in a furnace at $300{ }^{\circ} \mathrm{C}$ for $1 \mathrm{~h}$.

In order to compare the specimen temperatures from the diverse techniques in this investigation, six type N TCs at specific locations along the $25 \mathrm{~mm}$ specimen gauge section were used; top gauge face and edge $+12.5 \mathrm{~mm}$, centre gauge and face $0 \mathrm{~mm}$ and the bottom gauge face and edge $-12.5 \mathrm{~mm}$ as shown in Figure 6. Thermocouples were used to obtain a baseline temperature due to their low cost, simplicity of use, and because they are the most widely accepted measurement method in most mechanical testing standards [2,3]. The TCs were used to measure temperature at the test-piece surface from the upper, lower, and centre locations of the gauge section. These temperatures were then used to validate measurements taken from thermography and pyrometer at the same locations on the test piece.

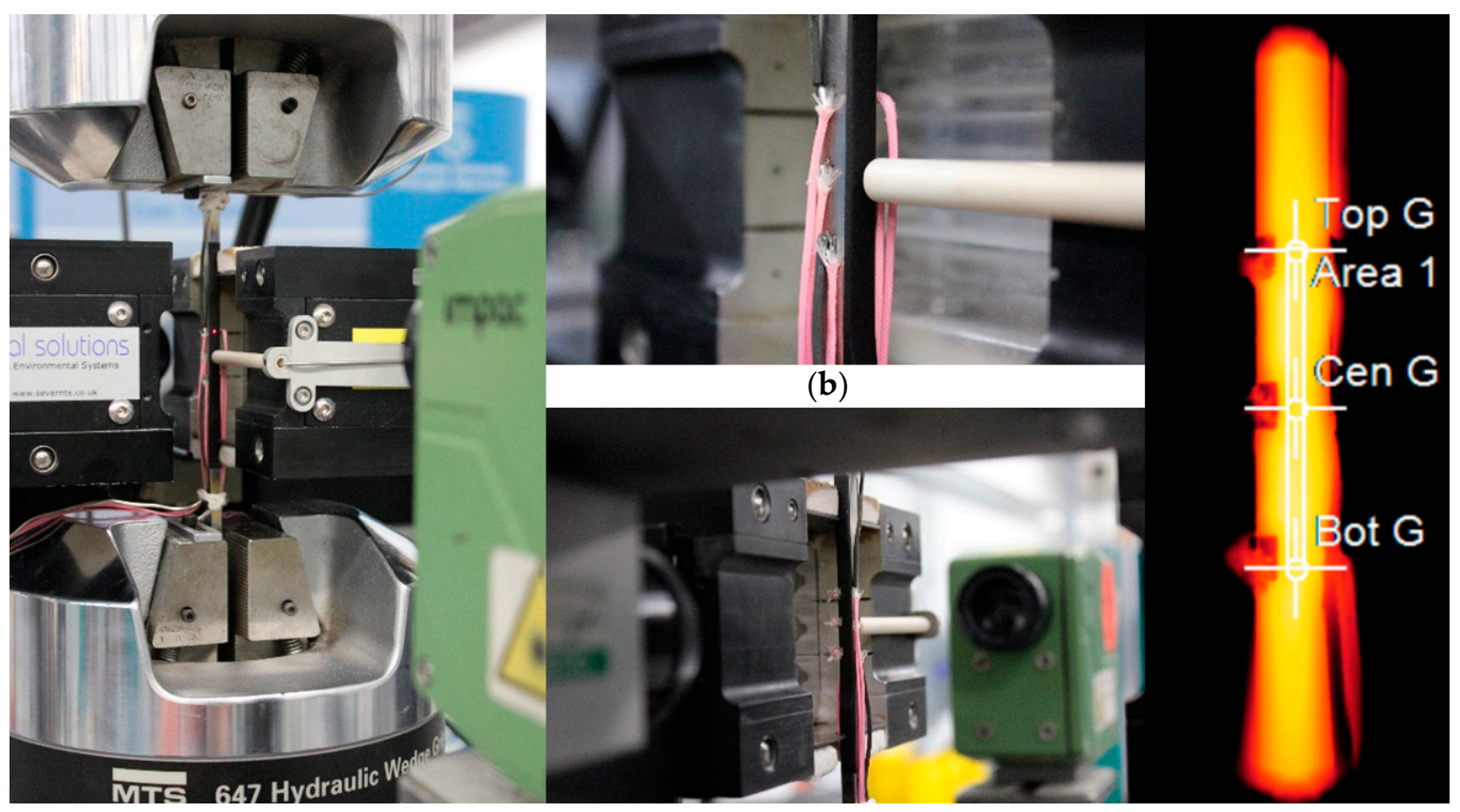

(a)

(c)

(d)

Figure 6. Comparison arrangement of the three temperature measurement techniques; thermocouple, pyrometer and thermography camera. (a) Front view, pyrometer aimed at the top of the test specimen gauge section; (b) Nickel base test specimen with six type-N thermocouples spot welded across a $25 \mathrm{~mm}$ gauge section at the upper lower and centre locations of two perpendicular specimen faces. Ceramic housing for a non-contact monitoring thermocouple is also visible; (c) Rear view, thermography camera aimed at HE23 coated specimen face; (d) A view of the test specimen and the attached TCs in Figure 3c through thermography.

\section{Results}

\subsection{Infra-Red Considerations}

Before thermography can be successfully employed, there are four primary considerations that must be taken into account which are; external influences, emissivity of the surface under investigation, the size and location of the area or single point to be measured, and, accurate alignment of the IR camera to the specimen surface. 


\subsubsection{External Influences}

Thermal radiation reflections emitted from reflective metallic surfaces can cause significant complications with temperature accuracy and as such, any reflective surface within a furnace must be covered with a high emissivity black coating. An example of thermal radiation reflections within a horizontal bulb configuration radiant lamp furnace are given in Figure 7a,b. Coating the internal reflective surfaces to avoid complications and inaccuracies with respect to radiation from nearby heat sources proved effective as seen in Figure $7 \mathrm{c}, \mathrm{d}$, where there is a clear reduction in thermal radiance providing a more accurate temperature distribution across the specimen.

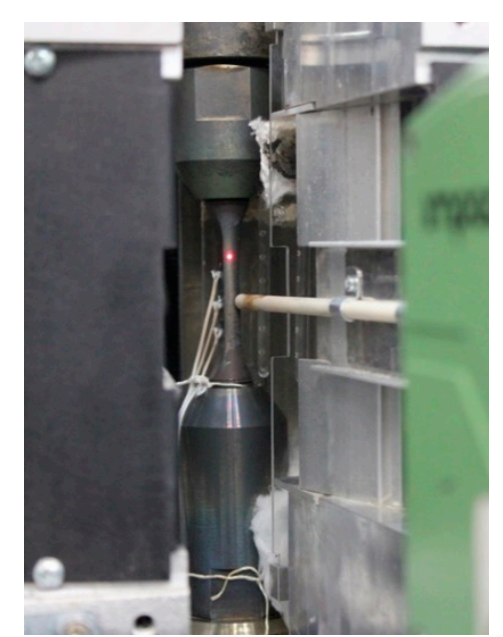

(a)

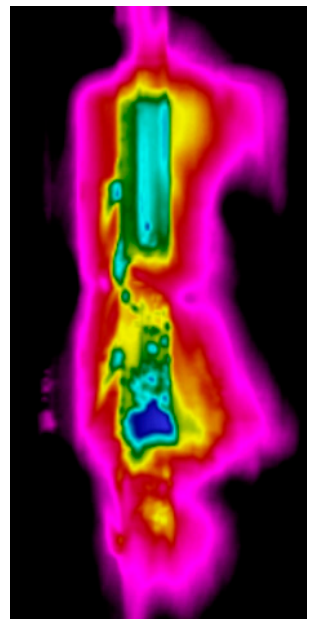

(b)

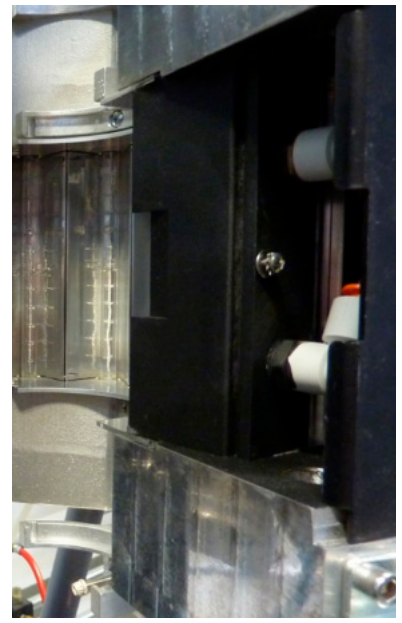

(c)

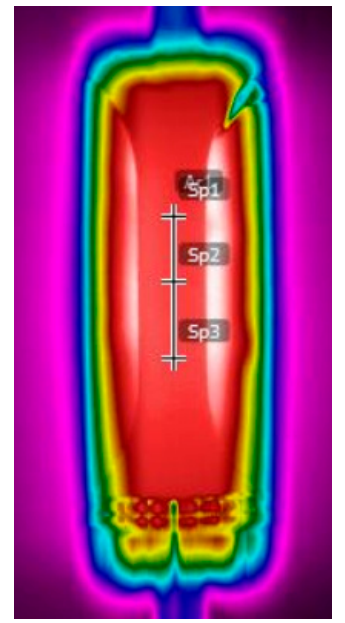

(d)

Figure 7. A $12 \mathrm{~kW}$ Infra-red radiant vertically mounted quartz lamp furnace (a) uncoated reflective internal furnace surfaces; (b) Thermography view of specimen through uncoated furnace shown in (a); (c) Internal furnace surface coated with HE23 thermal paint; (d) Thermography view of specimen through HE23 coated furnace shown in (c).

Thermocouples attached to a specimen's surface have been the primary method of temperature calibration outlined by the governing standards for mechanical tests involving dynamic temperature such as TMF. However, shown in Figure 8, are clear examples of insulation and thermal distortion caused by thermocouples attached to the surface of a test specimen. In Figure $8 \mathrm{a}$ when imaging a pre-oxidied metallic surface, the vast difference in emissivity between the TC sheathing and specimen surface, causes overexposure and image distortion. However, once thermocouples are removed as seen in Figure $8 \mathrm{~b}$, the non-uniformity of the pre-oxidised metallic surface still does not provide an accurate base for measurement, highlighting the need for stable and uniform surface preparation prior to thermography control upon un-coated metallic surfaces.

Clear hot spots exist beneath the point of contact of the tie-on TC, the insulating effect is magnified by spot welded thermocouples aligned along the specimen's surface, Figure $8 \mathrm{c}$. The effect exists upon both metallic and non-metallic materials, Figure 8d,e respectively. Specimens imaged without attached thermocouples show no distortion or hot spots and a well distributed, uniform thermal path exists, Figure $8 \mathrm{f}-\mathrm{h}$. 


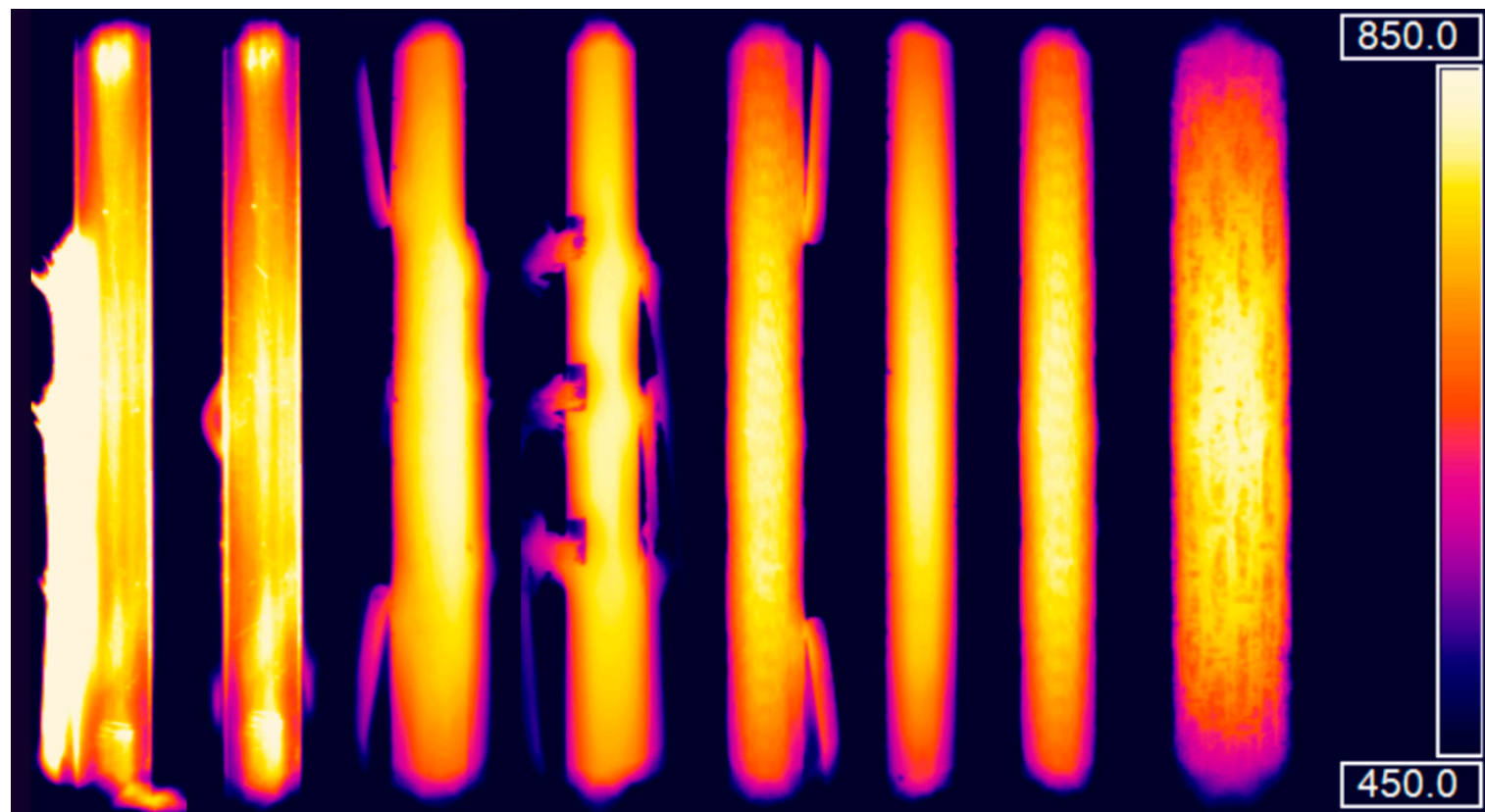

(a) (b)

(c)

(d)

(e)

(f)

(g)

(h)

(i)

Figure 8. View through thermography of a dog bone rectangular specimen at $800{ }^{\circ} \mathrm{C}$ inside a radiant lamp furnaces (RLF). (a) Metallic specimen with a pre oxidised polished surface, spot welded thermocouples are attached; (b) Metallic specimen with a pre-oxidised metallic surface; (c) Metallic specimen coated with HE23 thermal paint, spot welded and tie on thermocouples are attached; (d) Metallic specimen coated with HE23, six spot weld thermocouples are attached; (e) Ceramic specimen with tie on thermocouples attached; (f) Metallic specimen coated with HE23 thermal paint (g) Side view of a ceramic specimen; (h) Face view of ceramic specimen; (i) Temperature reference bar relating to images (a) to (h).

\subsubsection{Emissivity}

When using thermography or a pyrometer, for accurate temperature measurement it is essential to know the emissivity of the surface being measured. To assess the stability of thermography upon diverse surfaces, pre-oxidised, metallic, HE23 coated and ceramic surfaces were investigated to determine the time required to form a stable surface emissivity. Knowledge of the conditions at which a stable emissivity can be reached will allow test pieces to be heat treated/oxidised before testing, enabling a stable surface emissivity and accurate non-invasive temperature measurement to be achieved.

A thermocouple was attached to the centre of the test piece gauge sections and a pyrometer or infra-red camera was aimed aligned alongside, parallel to the TC. The ICS and RLF heat sources were controlled using a feedback loop from the non-invasive techniques to apply a constant temperature to the test piece whilst the temperature was monitored by the TC. The emissivity input of the pyrometer and infra-red camera was adjusted until the measured temperature returned was equivalent to that shown by the TC. These results can be seen in Figure 9. 


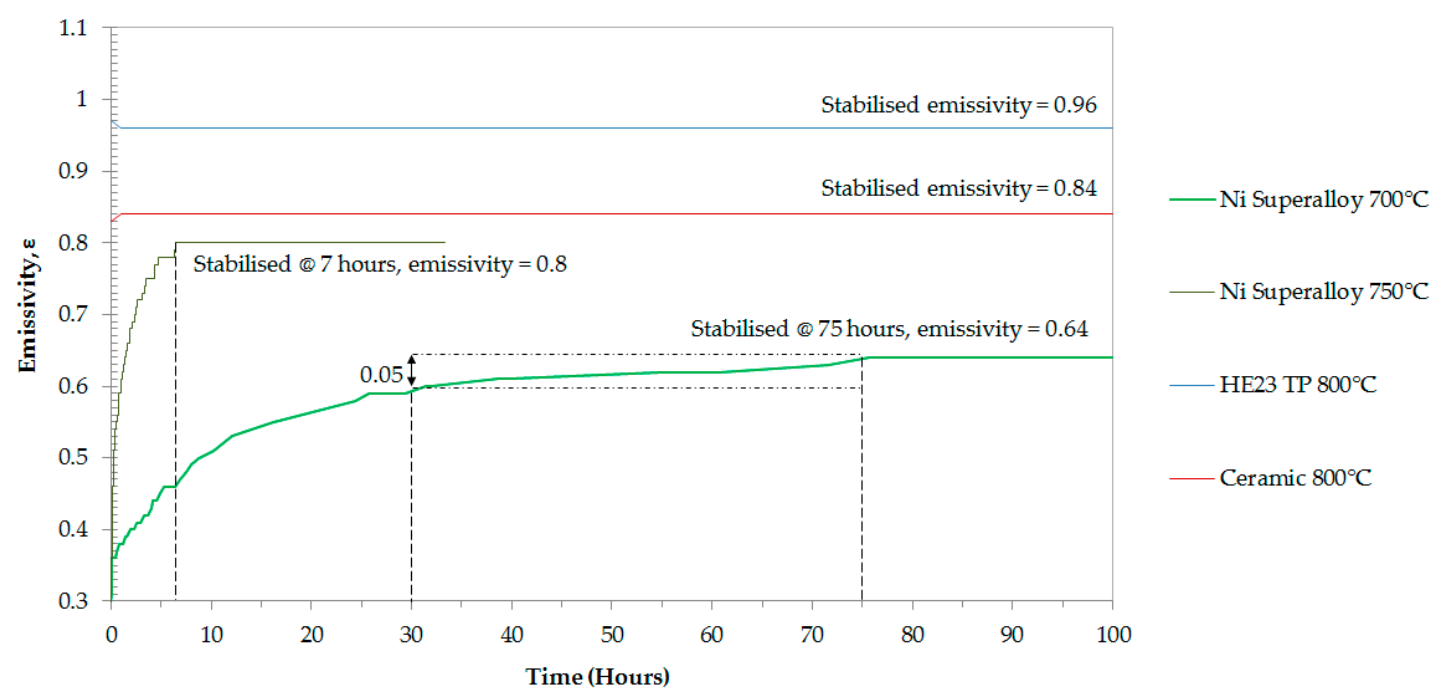

Figure 9. Isothermal surface emissivity calibration of a Ni superalloy at 700 and $750{ }^{\circ} \mathrm{C}, \mathrm{HE} 23 \mathrm{TP}$ coating and a ceramic specimen at $800{ }^{\circ} \mathrm{C}$.

In Figure 9, it shows that surface emissivity of the Ni alloy at a constant temperature of $700{ }^{\circ} \mathrm{C}$ does not stabilise until after $75 \mathrm{~h}$, with a resultant stabilised emissivity value of 0.64 . At $750{ }^{\circ} \mathrm{C}$ the rate of oxidation is higher and hence the rate of emissivity evolution is rapid with time at temperature. The surface emissivity stabilises after just $7 \mathrm{~h}$ at 0.8 , an increase of 0.16 compared to the stabilised emissivity value at $700{ }^{\circ} \mathrm{C}$. Consistent with previous work, the emissivity of the HE23 TP is stable; the emissivity was stable at, $\varepsilon=0.96$, for the duration of testing. Stability of the CMC surface was also stable for the duration of testing with an emission value of 0.84 .

However, once a stable surface emission has been achieved distortions and inaccuracies may still result from unevenly oxidised surfaces. Small differences in the oxidised polished metallic surface shown in Figure 10a, affect the accuracy of temperature readings through thermography with surface temperature variations along the centred $25 \mathrm{~mm}$ vertical $y$-axis seen to have a variance of greater than $50{ }^{\circ} \mathrm{C}$ from the target temperature, $800{ }^{\circ} \mathrm{C}$. Comparing this surface instability to that of a HE23 coated metallic specimen in Figure 10b, it is clear that HE23 thermal paint delivers a stable and uniform surface emission with temperature variations across the centred $25 \mathrm{~mm}$ vertical $y$-axis line profile are less than $15^{\circ} \mathrm{C}$. The HE23 delivers a smooth temperature distribution allowing comprehensive thermal analysis. When comparing these results with the un-coated ceramic surface in Figure 10c, a similar overall temperature variation across the $25 \mathrm{~mm}$ vertical $y$-axis to that of the HE23 TP coated specimen. However a distinct temperature undulation is present, as the $y$-axis profile crosses the differing weave orientations of the complex CMC structure. 


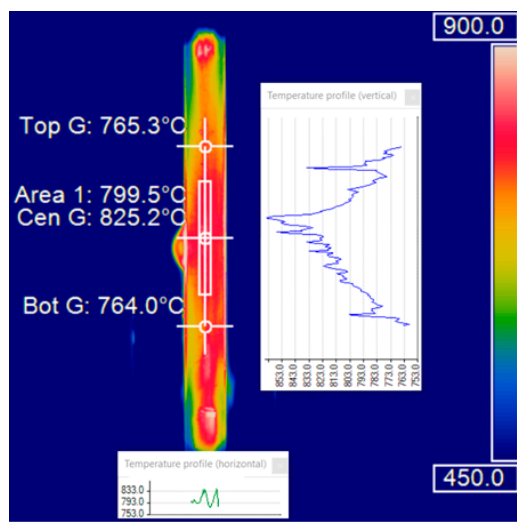

(a)

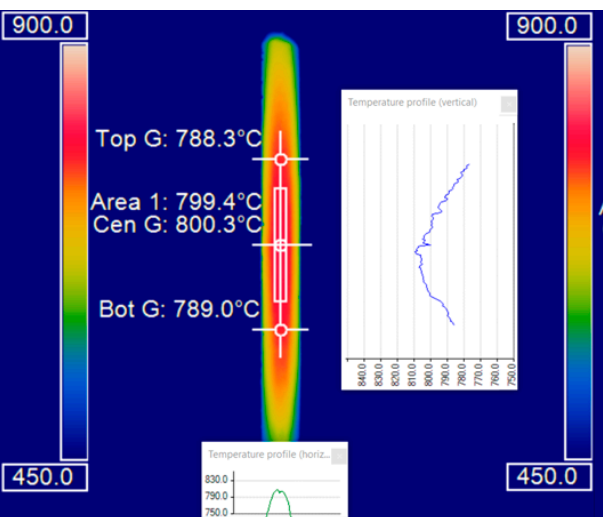

(b)

Figure 10. Thermography view of a dog bone rectangular specimen through the furnace window of the 2nd generation infra-red lamp furnace. (a) Pre-oxidised polished metallic surface; (b) HE23 thermal paints (TP) coated metallic surface; (c) Non-metallic un-coated ceramic surface.

\subsubsection{Size and Location of Control Area}

A powerful advantage of thermography over thermocouples and pyrometers is that the size, location and mode of temperature control are flexible. Every surface in view can be measured, however, depending on the specimen geometry and material a number of options can be taken. During this investigation it was found that when using flat HE23 coated surfaces a single measurement point (SP) or a user defined area control, gave accurate temperature readings in comparison to spot welded thermocouples as seen in Figure 11a,b. This was the case when using both the averaging and maximum temperature command outputs.

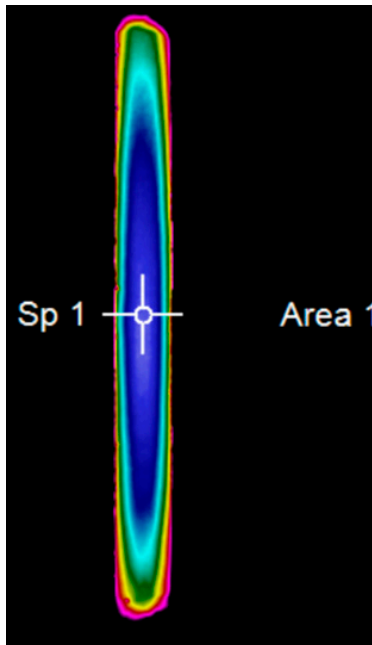

(a)

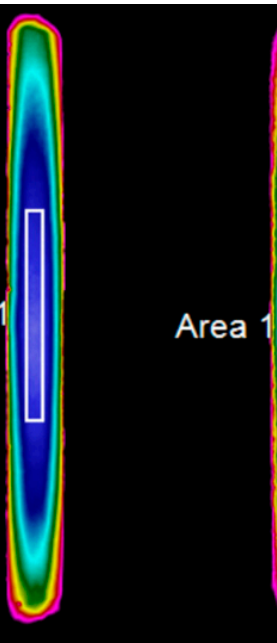

(b)

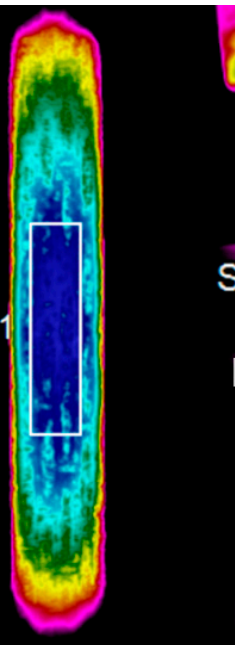

(c)

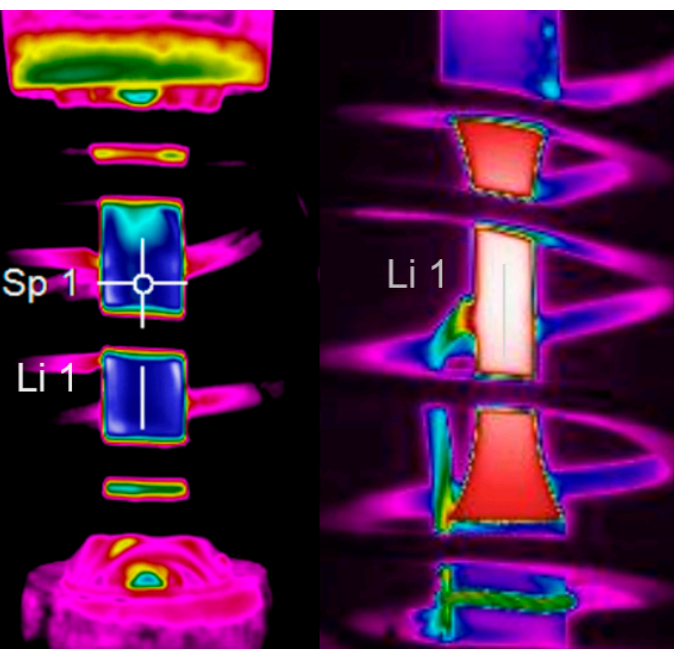

(d)

(e)

Figure 11. Size and location of possible measurement points and areas employed during the thermography control method. (a) Single point control; $(\mathbf{b}, \mathbf{c})$ Average area control through a furnace window; (d) Single point control; (d,e) Average line control possible through induction coil designs.

Throughout the investigation it was noted that when using uneven surfaces, due to either oxide growth or material structure, it was difficult to ensure accuracy. In such circumstances with uneven structures or non-uniform surface emissions, controlling temperature by averaging over the entire control zone proved most accurate, Figure 11c. However, the emissivity of an object is known to vary with the angle at which you are measuring [30]. Thus, when controlling temperature of surfaces that 
are not flat such as cylindrical surfaces, the most accurate results were obtained using either a SP or averaging Line control down the centre of the specimen's $y$-axis, Figure 11d. In some instances where helical induction coil configurations are used, areas of the specimen are shadowed and could not be measured, Figure 11e.

\subsection{Measurement Technique Comparisons}

\subsubsection{Isothermal Temperature}

To compare thermography control to thermocouple and pyrometer control, as well as, time dependent effects of degradation at temperature upon accuracy, a fifty-five hour $800{ }^{\circ} \mathrm{C}$ isothermal test was undertaken. A Nimonic 90 dog bone specimen was coated in HE23 and temperature was controlled by thermography averaging over an area. Measured values from the three techniques were compared at the top, centre and bottom locations of a $25 \mathrm{~mm}$ gauge section, Figure 12. Accuracy was found to be within $\pm 2{ }^{\circ} \mathrm{C}$ of when comparing all techniques at each location for the duration of the test with no indication of any adverse effects on the HE23 TP coating or accuracy of the non-invasive technique from oxidation, etc.

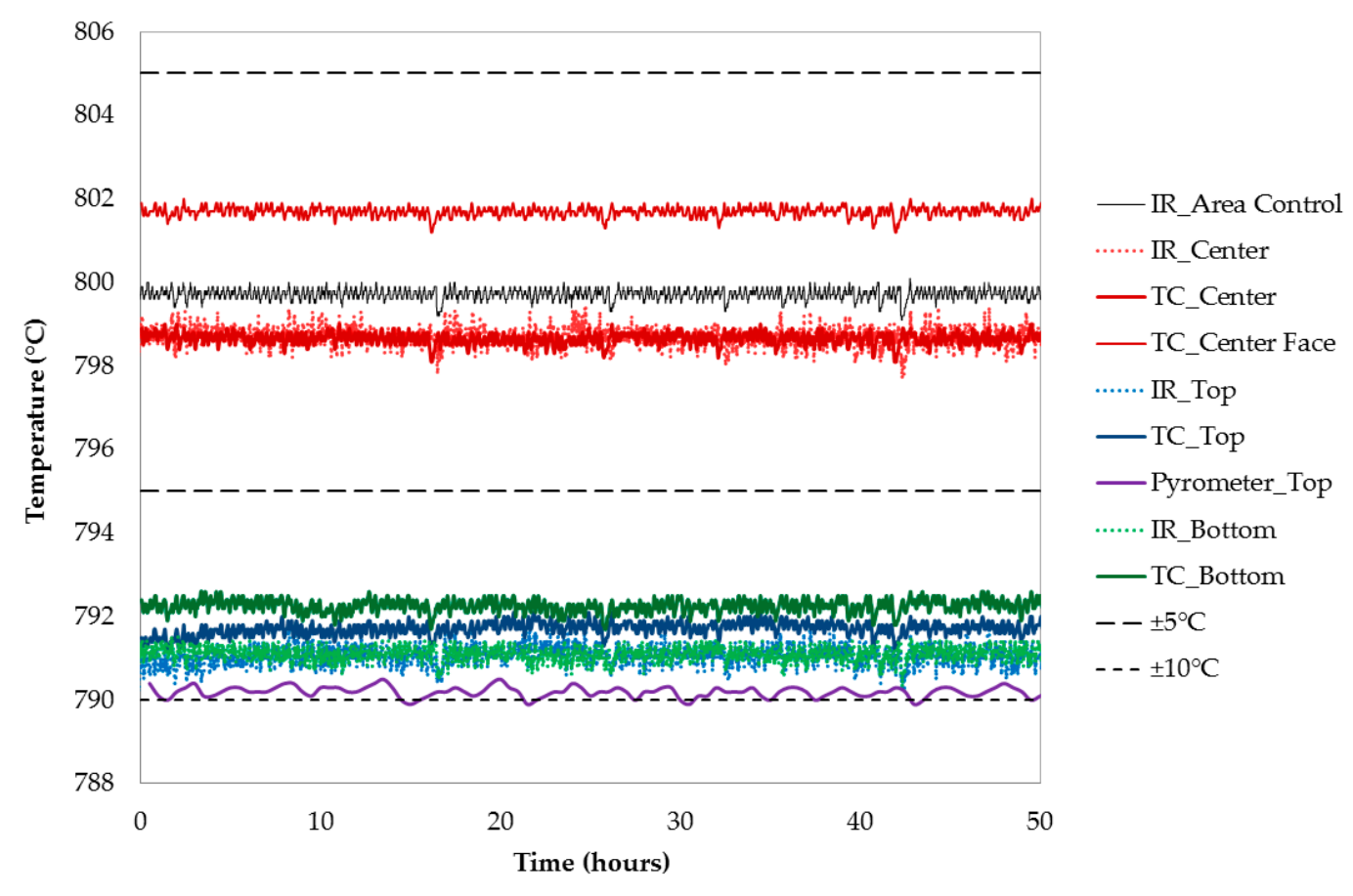

Figure 12. Isothermal stability of thermography control under RLF heating at $800{ }^{\circ} \mathrm{C}$ upon metallic specimen coated in HE23.

\subsubsection{Dynamic Temperature}

The previously described method of was applied dynamic thermal cycles in the form of a trapezoidal dwell waveform, more commonly described as a flight cycle in the gas turbine sector. Thermal waveforms were undertaken using both ICS and RLF heating sources over a 550-800 ${ }^{\circ} \mathrm{C}$ temperature range. Temperatures were monitored by spot welded, tie-on and non-contact thermocouples, as well as, a pyrometer at centre of the test piece gauge section. Typical responses from each of the techniques under RLF heating are shown in Figure 13. 


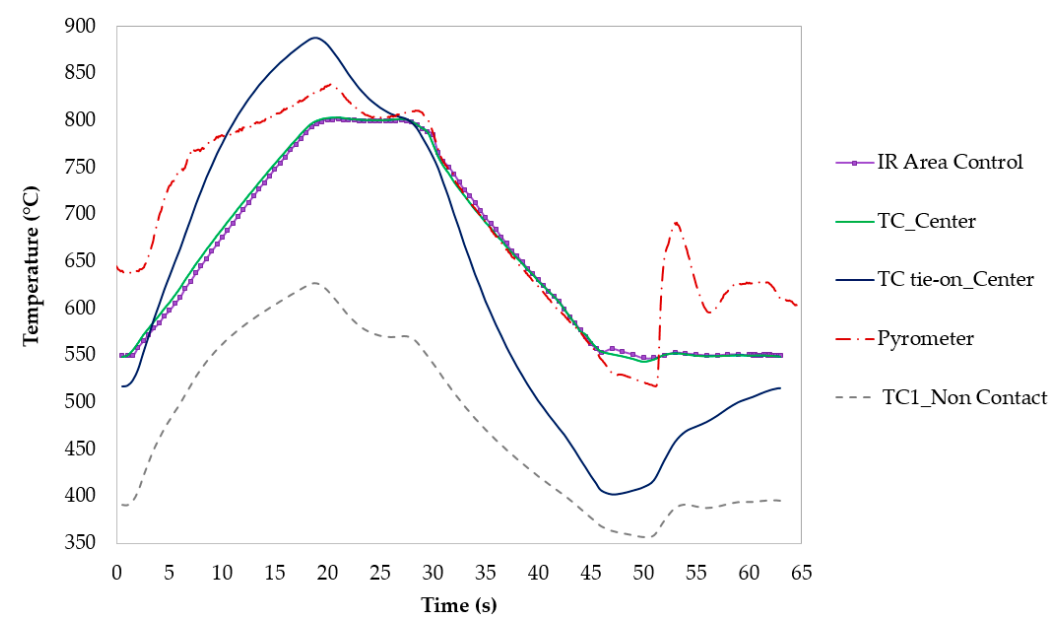

Figure 13. Dynamic temperature response comparison utilising thermography area control, under RLF furnace heating upon a metallic HE23 coated specimen.

The response from the spot-welded thermocouple closely follows that of the thermography area control, however the response from the tie-on thermocouple and pyrometer did not. The tie-on thermocouple overshoots and undershoots the temperature control target during the heating and cooling turning points. The pyrometer displayed a similar response to the tie-on thermocouple, albeit far less stable at lower temperatures. Clear interference between the wavelength of infra-red pyrometer and RLF is evident. As expected the non-contact thermocouple, shielded within a ceramic tube and not in contact with the specimen did not hit the minimum and maximum commanded temperatures. However, a repeatable waveform was achieved, this can be used to assess the long-term stability of specimen temperatures under thermography control and monitor highlight any potential temperature deviations and or drifting.

A more detailed comparison of the temperature deviation between the thermography area control and monitoring spot welded TC during dynamic thermal cycling is given in Figure 14a. Typically thermocouples measure within $\pm 2{ }^{\circ} \mathrm{C}$ of the thermography area control for all tests during isothermal or constant temperature portions of the cycles. However, significant temperature differences up to $10{ }^{\circ} \mathrm{C}$ were found during heating and cooling turning points of the dynamic thermal cycles, Figure $14 \mathrm{~b}, \mathrm{c}$. During the isothermal dwell stages of the waveform accuracy returned to within $\pm 2{ }^{\circ} \mathrm{C}$.

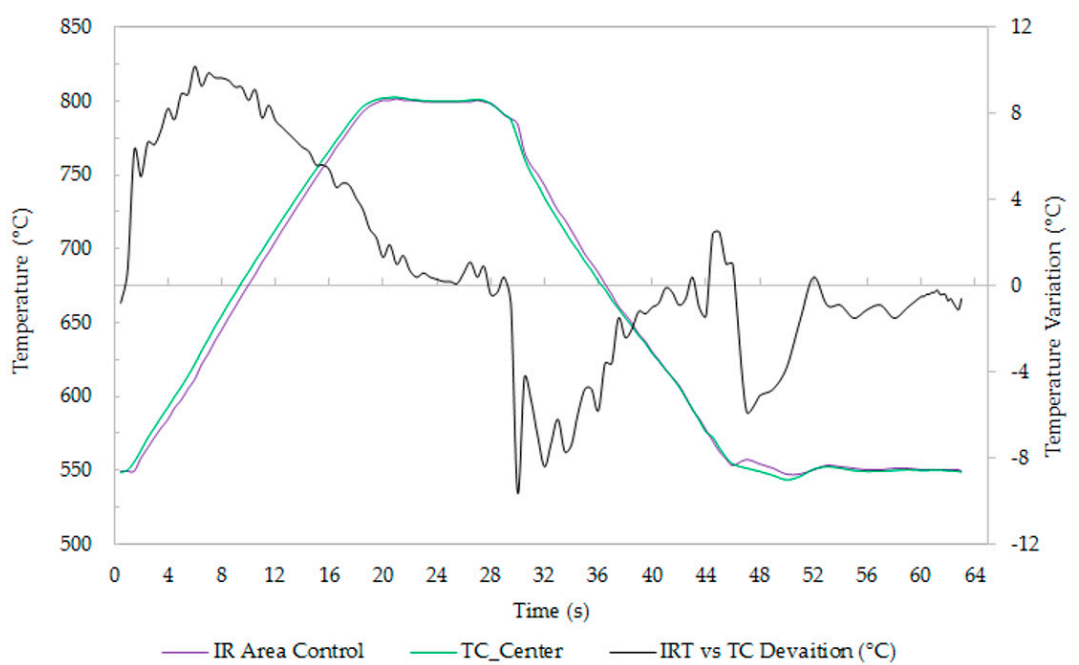

(a)

Figure 14. Cont. 


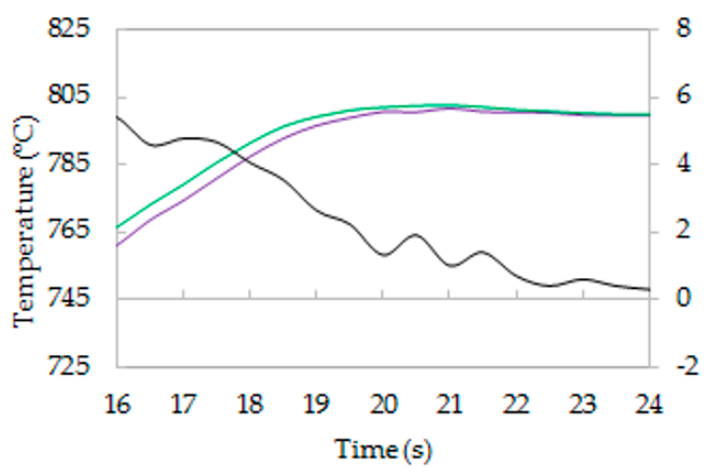

(b)

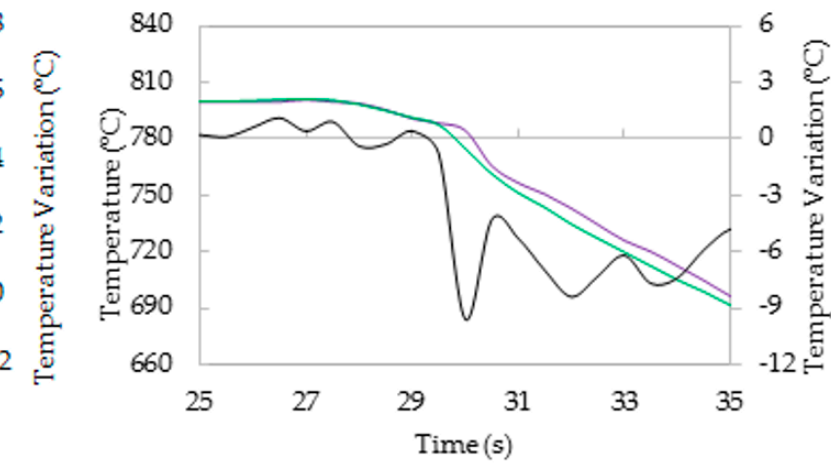

(c)

Figure 14. (a) Dynamic temperature turning point response comparison between spot welded thermocouples and thermography area control upon metallic HE23 coated specimen; (b,c) Typical response during the heating and cooling turning points respectively.

A significant advantage of thermography is its ability to measure non-metallic materials during dynamic thermal cycling when thermocouples cannot be spot welded to the non-conductive ceramic material and the stability of a pyrometer is not accurate enough under RLF heating. As such a non-contact thermocouple was installed to capture a secondary measurement of long term peak cycle temperatures. Results of the peak cycle temperatures of both the thermography area control and the non-contact TC are given in Figure 15. Thermal testing ran for over 10,000 cycles, equivalent to $270 \mathrm{~h}$. No drift in peak cycle temperatures was found in either the thermography area control or non-contact monitoring TC.

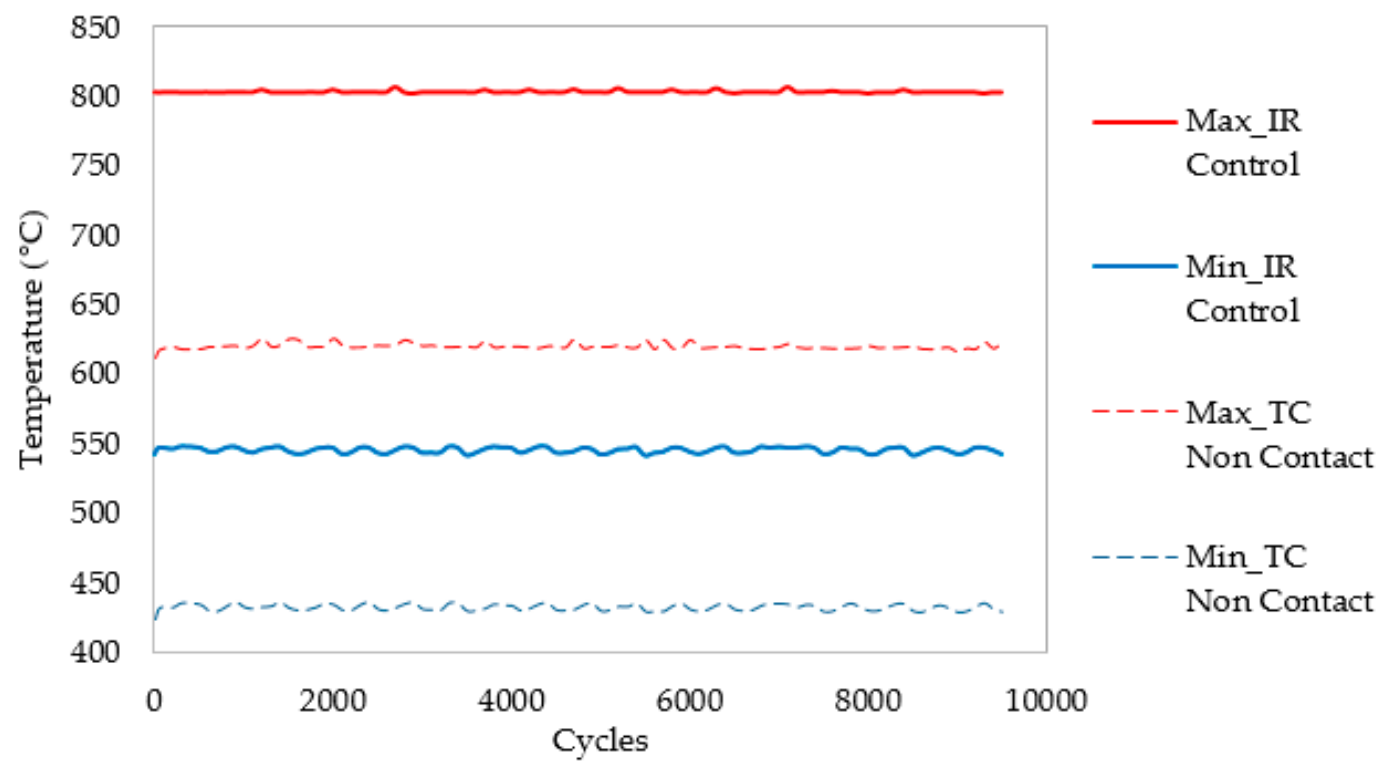

Figure 15. Dynamic peak cycle temperature stability using thermography area control upon ceramic uncoated specimen.

\subsection{Unique Benefits of Thermography}

\subsubsection{Test Analysis and Setup}

In comparison to the current methods recommended to control dynamic temperature, thermography has enormous potential. Facilitating the entire specimen gauge section being viewed, monitored and controlled is an exclusive advantage alone to this technique. An additional advantage 
is that the entire test can be recorded and comprehensively examined post-test. This information could potentially provide additional links uncovering the effects of any identified hot/cold spots with sites of early crack initiation or potential signs towards onset of failure.

Temperature ranges and modes can be tailored to suit the current objective of the operator, allowing extensive examination of temperature paths and gradients. An example of the comprehensive analysis possible is given in Figure 16. Single point measurements across the specimen gauge section are tracked and recorded in Figure 16a, temperature range is relative to the thermal cycle employed, $800-550{ }^{\circ} \mathrm{C}$. A more detailed examination of the specimen at the peak cycle temperature of $800{ }^{\circ} \mathrm{C}$, is shown in Figure 16b. The temperature range has been narrowed to reveal the complex hot and cold spots across a complex ceramic woven structure. Vertical, $y$-axis and horizontal $x$-axis temperature paths are recorded.

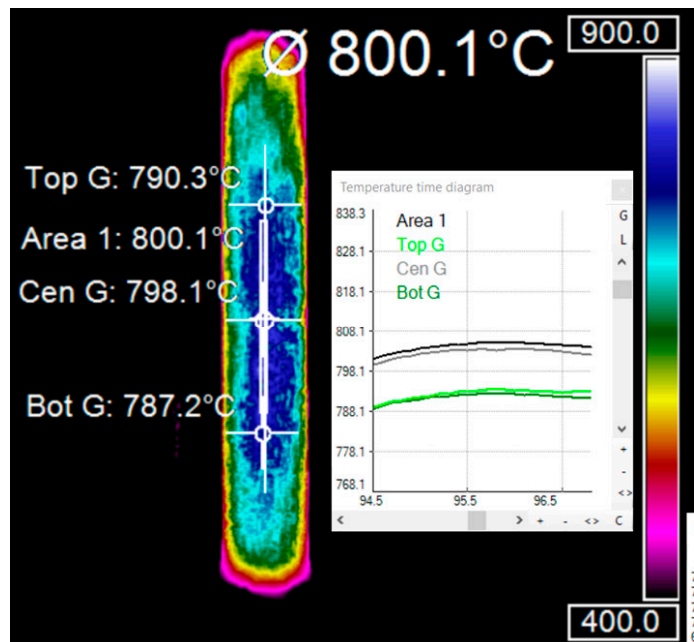

(a)

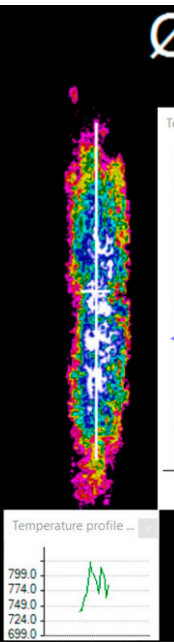

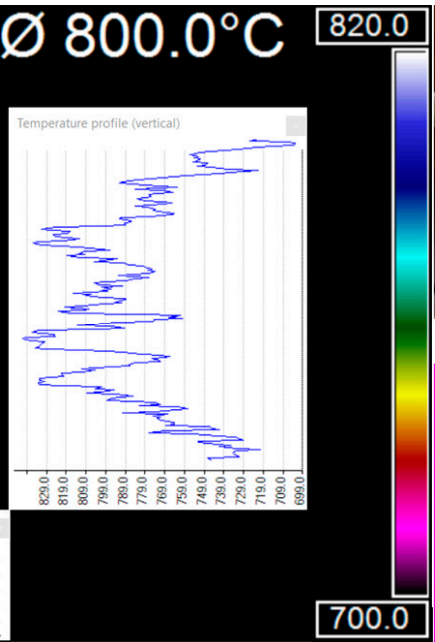

(b)

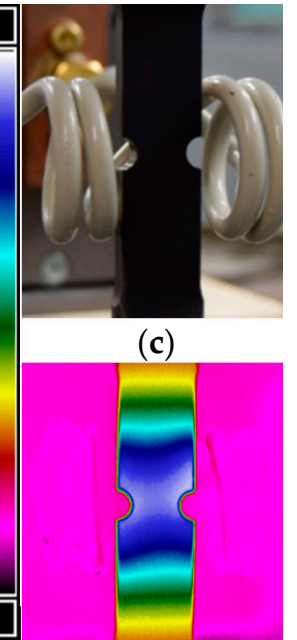

(d)

Figure 16. Overview of the additional scope and visibility of temperatures thermography can provide. (a) Temperature range is relative to the employed $550-800{ }^{\circ} \mathrm{C}$ thermal cycle, single point and area measurements are recorded, through a time/temperature plot; (b) Reduced temperature range to uncover intricate temperature maps across the complex ceramic composite material (CMC) structure at the peak cycle temperature, $800{ }^{\circ} \mathrm{C}$. Line temperature profiles along the specimen $X$ and $Y$-axis are displayed; (c) Double notched specimen coated with HE23 TP within a complex split transversal electromagnetic field helical induction coil; (d) Non-uniform temperature distribution is clearly visible using thermography across a double notched specimen coated with HE23 TP within a complex split transversal electromagnetic field helical induction coil given in Figure 16c.

In the current investigation the thermography technique has proved effective not only to control temperature of both metallic and non-metallic specimens, but during thermal profiling and test setup. An example of a double notched specimen coated with HE23 TP within a complex split transversal electromagnetic field helical induction coil is given in Figure 16c. Typically, it is difficult to achieve uniform temperature distributions during thermal profiling using such a complex electromagnetic field in combination with thermocouples. Moreover, only the small areas captured by the thermocouples can be characterised. Using thermography, thermal distributions were clearly visible and test setups could be adjusted in-situ to achieve the desired temperature distributions. An example of a non-uniform temperature distribution generated by a transversal electromagnetic field is given in Figure $16 \mathrm{~d}$. The thermal hot spot is not centred and aligned across the notch gauge sections. Using this technique, a simple adjustment in alignment and position of coil, in-situ, enabled the desired temperature distribution to be achieved. 


\subsubsection{Crack Growth Measurements}

Thermography has been utilised to measure crack growth at ambient, isothermal and dynamic temperatures. The infra-red camera was aligned to the tip of a machined $0.2 \mathrm{~mm}$ corner starter slit in a $7 \times 7 \mathrm{~mm}$ test specimen. Example thermographic images taken of crack growth at $750{ }^{\circ} \mathrm{C}$ under IP TMF loading are given in Figure 17. Crack growth down to $0.1 \mathrm{~mm}$ in length has been detected and recorded using this technique. Work is on-going comparing the visual non-invasive thermography measurements with the direct current potential drop (DCPD) technique [32], where a current is applied to the specimen and probes detect the potential difference across the cracked surface as damage progresses.

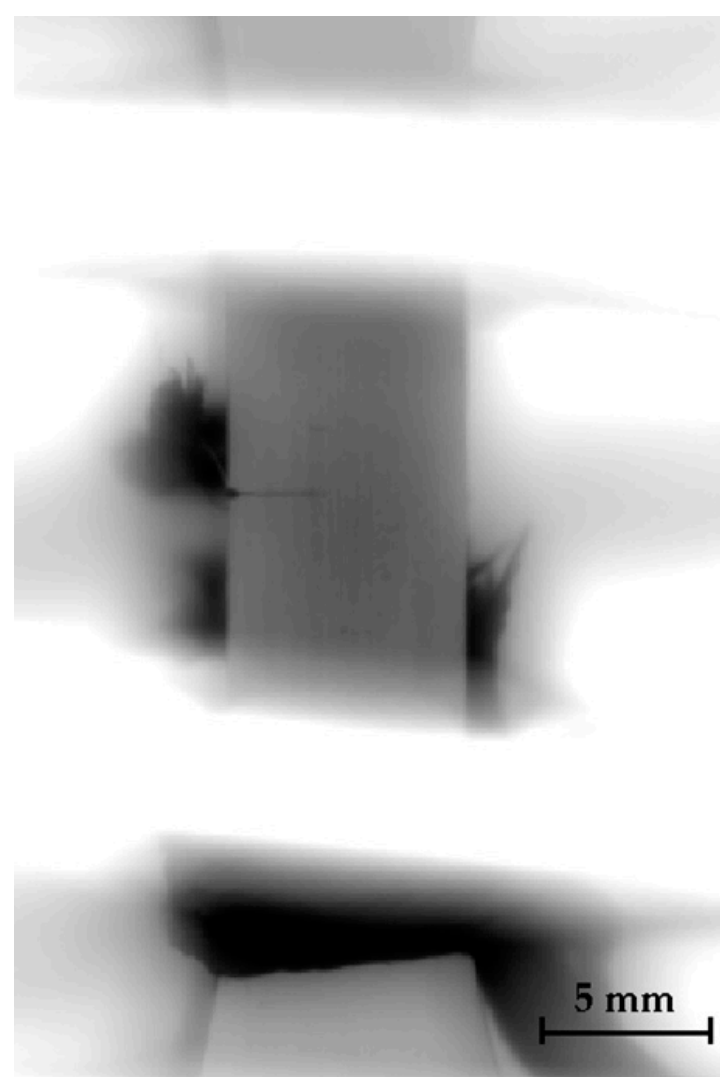

(a)

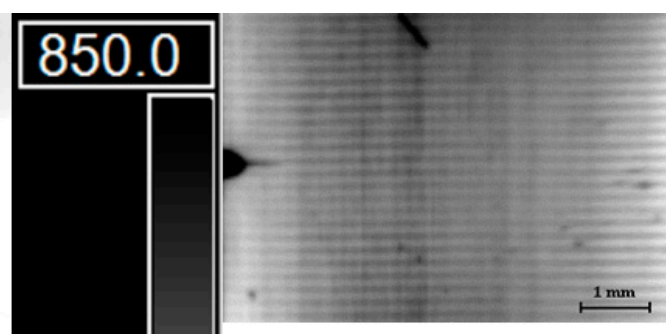

(b)

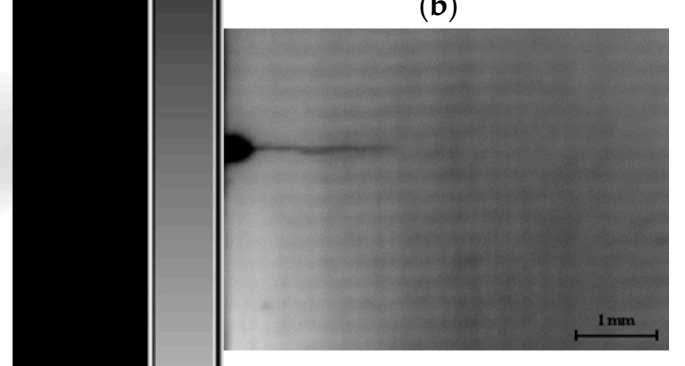

(c)

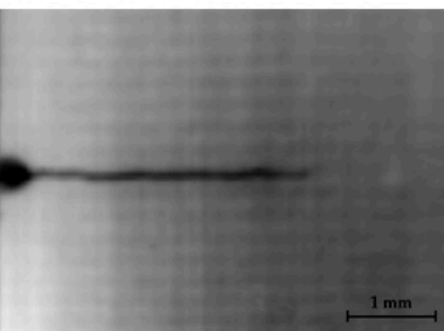

(d)

Figure 17. Thermographic image of a Ni-base superalloy $7 \times 7 \mathrm{~mm}$ corner cracked specimen under induction coil systems (ICS) heating during In-Phase thermo-mechanical fatigue (TMF) cycling. Thermographs are taken at peak load and temperature, $750{ }^{\circ} \mathrm{C}$. (a) View of the entire specimen gauge section within an ICS; (b) Magnified view of starter notch and initial crack growth; (c) Magnified view of starter notch and secondary crack growth (d) Magnified view of the starter notch and further crack growth.

\section{Discussion}

The bespoke thermography based mechanical test setup for non-metallic materials testing at high temperature has proven to be an excellent means to assess these materials under arduous conditions. It has been shown in this work that in circumstances where external thermal radiation can be kept to a minimum, and a stable and known surface emissivity exists, accurate temperature control can be achieved through thermography. Careful selection of the control mode and point, area or line-based control is crucial and is ultimately determined by the combination of heating technique and specimen geometry. The addition of the non-contact monitoring thermocouple within the bespoke thermography based mechanical test setup provides an additional means of measurement to ensure accuracy. 
Trials to achieve a stable surface emissivity were successful upon the three surfaces investigated, metallic, HE23 TP coated, and a non-metallic ceramic. The HE23 TP provided a stable surface emissivity of 0.96 at $800{ }^{\circ} \mathrm{C}$ consistent with previous work, [30]. In the author's experience, meticulous care must be taken with metallic surface preparation prior to exposure to ensure a uniform surface, enabling accurate and repeatable temperature control. Despite achieving uniformity, a negative effect on fatigue life has been previously reported as a result of such pre-test thermal exposure [27]. Concerns to this effect could be justified when considering the timescale to surface stabilisation of the Ni superalloy at $700{ }^{\circ} \mathrm{C}$, Figure 9. Although the surface emissivity did not fully stabilise until after $75 \mathrm{~h}$ of exposure, it should be noted that the rate of emissivity evolution with time reduced significantly after $24 \mathrm{~h}$. Indeed, the surface emissivity increased by only $0.05(0.59-0.64)$ in $51 \mathrm{~h}$ of exposure at $700{ }^{\circ} \mathrm{C}$ after the initial $24 \mathrm{~h}$ of exposure. Considering this stabilisation timescale is at the peak isothermal temperature of a dynamic test, $24 \mathrm{~h}$ of pre-exposure could be justified to limit any negative effect on fatigue life whilst ensuring a stable surface condition.

Despite the efforts to achieve a stable surface emissivity from a metallic surface within a timescale suitable not to impact on fatigue life, uncertainties still exist with regard to the accuracy of non-invasive temperature measurement. Despite efforts to meticulously prepare metallic test specimen surfaces prior to heat treatments, inhomogeneous surfaces can still prevail. These surface inconsistences cause severe inaccuracy across measured surfaces, Figure 10a. However, both the HE23 TP coated and ceramic surfaces delivered a stable surface emission and thus accurate temperature control, allowing detailed visualisation of thermal gradients, Figure 10b. It must be noted that slight differences were seen in the surface emission of the complex woven ceramic structure between the fibres and surrounding matrix, Figure 10c. However, controlling the temperature through thermography by averaging over an area dissipated this effect and provided excellent accuracy in comparison to tie on thermocouples at isothermal temperatures.

The accuracy of thermography and pyrometry persisted in comparison to thermocouples upon the HE23 coated and ceramic surfaces at the three locations compared across the chosen $25 \mathrm{~mm}$ specimen gauge length during isothermal conditions, Figure 12. Accuracy was maintained for over $50 \mathrm{~h}$ to within $\pm 2{ }^{\circ} \mathrm{C}$. However, during dynamic thermal cycling significant inaccuracies were found between the techniques employed, Figure 13. Readings from the pyrometer are inaccurate, suggesting the wavelength emitted from the RLF is significantly obscuring its accuracy during dynamic cycling. At first glance spot welded thermocouple and thermography readings appear in symmetry whilst it is clear that the tie-on thermocouple substantially over and undershoots the control waveform.

This behaviour was noted in previous work [11], the small mass of the thermocouples gives rise to rapid temperature changes. Thermocouples appear to absorb heat energy during heating stages of the cycle and shed heat during the cooling stage. This gives rise to different ramp rates and, directly compared to thermography, inaccurate temperature readings. This effect also seems to appear on closer inspection of the symmetry between readings from thermography control and the spot-welded thermocouple, during the heating and cooling stages of dynamic cycles, Figure 14. Accuracy then recovers to within $\pm 2{ }^{\circ} \mathrm{C}$ during isothermal stages of the cycle, again consistent with previous work, [11,13].

Consistent with previous work $[11,13]$, thermocouples on the specimen gauge section have shown to generate significant complications, Figure 8. In this investigation thermocouples have shown to induce thermal hot spots, insulating the test piece surface beneath them as well as distorting thermography readings. In previous work thermocouples have also been shown to cause significant inaccuracies due to shadowing effects, $[11,13]$. Not only does the non-invasive thermography technique avoid such complications but could also provide additional benefits by locating any hot/cold spots and connecting them to sites of crack initiation or the onset of failure.

Historic optical methods to measure crack growth provide a simple approach to crack monitoring, however the sensitivity is significantly reduced in comparison to DCPD methods, and also may be 
restricted by the heating apparatus being utilised. Thermography has the potential to control test temperature as well as providing an accurate means of crack growth monitoring.

\section{Conclusions}

Thermography can provide an extensive overview of test temperatures and improve accuracy over traditional methods, provided a stable surface emissivity exists. Modern pyrometers are now capable of adjusting for evolving surface emission whilst on-going work into developing methods of emissivity correction based on the direct processing of the output signal from infra-red cameras is on-going.

Finally, if thermography is recognised as a standardised method of dynamic high temperature control in advanced and definitive mechanical testing scenarios additional investigations must be undertaken. These include; temperature stability assessments of both pre oxidised surfaces, TP coatings and thermography feedback signals over long term durations. The ability of the thermography technique to maintain accuracy during extensive plastic deformation. Conclusive and reliable traceability of calibration procedures and accuracy for test house accreditation commitments.

Acknowledgments: This project has received funding from the European Union's Horizon 2020 research and innovation programme and Joint Undertaking Clean Sky 2 under grant agreement No. 686600. Special thanks is given to Mark Whittaker, Robert Lancaster and Svjetlana Stekovic for help and support throughout the research.

Author Contributions: The author has made substantial contributions to conception and design of the practical setups utilized, furthermore all acquisition of as well as the analysis and interpretation of data. The author is responsible for drafting the article as well as revising it critically for important intellectual content. Finally the author has given final approval of the version to be submitted and any revised version thereafter.

Conflicts of Interest: The author declares no conflict of interest.

\section{References}

1. Lancaster, R.J.; Whittaker, M.T.; Williams, S.J. A review of thermo-mechanical fatigue behaviour in polycrystalline nickel superalloys for turbine disc applications. Mater. High Temp. 2013, 30, 2-12. [CrossRef]

2. American Society for Testing and Materials (ASTM). Standard Practice for Strain Controlled Thermomechanical Fatigue Testing; E2368-10; ASTM International: West Conshohocken, PA, USA, 2010.

3. International Organization for Standardization (ISO). Metallic Materials, Fatigue Testing, Strain-Controlled Thermomechanical Fatigue Testing Method; ISO 12111:2011(en); International Organization for Standardization (ISO): 389 Chiswick High Road, London, UK, 2011; p. 25.

4. Pahlavanyali, S.; Drew, G.; Rayment, A.; Rae, C.M.F. Thermo-mechanical fatigue of a polycrystalline superalloy: The effect of phase angle on TMF life and failure. Int. J. Fatigue 2008, 30, 330-338. [CrossRef]

5. Hähner, P.; Rinaldi, C.; Bicego, V.; Affeldt, E.; Brendel, T.; Andersson, H.; Beck, T.; Klingelhöffer, H.; Kühn, H.; Köster, A. Research and development into a European code of practice for strain controlled thermo-mechanical fatigue testing. Int. J. Fatigue 2008, 30, 372-381. [CrossRef]

6. Kuhn, H.; Kahlcke, O.; Brookes, S. A practicable nominal temperature tolerance for TMF-tests. Int. J. Fatigue 2008, 30, 277-285. [CrossRef]

7. Brendel, T.; Affeldt, E.; Hammer, J.; Rummel, C. Temperature gradients in TMF specimens. Measurement and influence on TMF life. Int. J. Fatigue 2008, 30, 234-240. [CrossRef]

8. European Commission. Validated Code-of-Practice for Thermo-Mechanical Fatigue Testing; EUR 22281 EN; Hähner, P., Affeldt, E., Beck, T., Klingelhöffer, H., Loveday, M., Rinaldi, C., Eds.; European Commission Joint Research Centre, Institute for Energy: Petten, The Netherlands, 2006.

9. Andersson, H.; Sjostrom, E. Thermal gradients in round TMF specimens. Int. J. Fatigue 2008, 30, $391-396$. [CrossRef]

10. Brookes, S.P.; Kühn, H.-J.; Skrotzki, B.; Klingelhöffer, H.; Sievert, R.; Pfetzing, J.; Peter, D.; Eggeler, G. Axial-torsional thermomechanical fatigue of a near- $\gamma$ TiAl-alloy. Mater. Sci. Eng. A 2010, 527, 3829-3839. [CrossRef]

11. Jones, J.; Brookes, S.P.; Whittaker, M.T.; Lancaster, R.J. Non-invasive temperature measurement and control techniques under thermomechanical fatigue loading. Mater. Sci. Technol. 2014, 30, 1862-1876. [CrossRef] 
12. Jones, J.; Whittaker, M.; Lancaster, R.; Williams, S. The influence of phase angle, strain range and peak cycle temperature on the TMF crack initiation behaviour and damage mechanisms of the nickel-based superalloy, RR1000. Int. J. Fatigue 2017, 98, 279-285. [CrossRef]

13. Jones, J.P.; Brookes, S.; Whittaker, M.; Lancaster, R.; Ward, B. Assessment of Infrared Thermography for Cyclic High-Temperature Measurement and Control. In Evaluation of Existing and New Sensor Technologies for Fatigue, Fracture and Mechanical Testing, 4th ed.; ASTM International: Toronto, ON, Canada, 2015.

14. Rosa, G.L.; Risitano, A. Thermographic methodology for rapid determination of the fatigue limit of materials and mechanical components. Int. J. Fatigue 2000, 22, 65-73. [CrossRef]

15. Audenino, A.L.; Crupi, V.; Zanetti, E.M. Thermoelastic and Elastoplastic Effects Measured by Means of A Standard Thermocamera. Exp. Tech. 2004, 28, 23-28. [CrossRef]

16. Bathias, C. Coupling effect of plasticity, thermal dissipation and metallurgical stability in ultrasonic fatigue. Int. J. Fatigue 2014, 60, 18-22. [CrossRef]

17. Beck, T.; Rau, K. Temperature measurement and control methods in TMF testing-A comparison and evaluation. Int. J. Fatigue 2008, 30, 226-233. [CrossRef]

18. Herve, P.; Cedelle, J.; Negreanu, I. Infrared technique for simultaneous determination of temperature and emissivity. Infrared Phys. Technol. 2012, 55, 1-10. [CrossRef]

19. Renier, E.; Meriaudeau, F.; Suzeau, P.; Truchetet, F. CCD temperature imaging: Applications in steel industry. In Proceedings of the 1996 IEEE IECON 22nd International Conference on Industrial Electronics, Control, and Instrumentation, Taipei, Taiwan, 9 August 1996.

20. Valiorgue, F.; Brosse, A.; Naisson, P.; Rech, J.; Hamdi, H.; Bergheau, J.M. Emissivity calibration for temperatures measurement using thermography in the context of machining. Appl. Therm. Eng. 2013, 58, 321-326. [CrossRef]

21. Bagavathiappan, S.; Lahiri, B.B.; Saravanan, T.; Philip, J.; Jayakumar, T. Infrared thermography for condition monitoring-A review. Infrared Phys. Technol. 2013, 60, 35-55. [CrossRef]

22. Roebuck, B.; Edwards, G.; Gee, M.G. Characterisation of oxidising metal surfaces with a two colour pyrometer. Mater. Sci. Technol. 2005, 21, 831-840. [CrossRef]

23. Lu, G.X.; Hao, L.J.; Liu, C.; Ye, F.X. Thermal analysis and failure behaviour of YSZ thermal barrier coatings on low heat rejection diesel engine piston. Mater. Sci. Technol. 2014, 30, 1273-1281. [CrossRef]

24. Davies, M.A.; Ueda, T.; M'saoubi, R.; Mullany, B.; Cooke, A.L. On The Measurement of Temperature in Material Removal Processes. CIRP J. Manuf. Sci. Technol. 2007, 56, 581-604. [CrossRef]

25. Neuer, G.; Jaroma-Weiland, G. Spectral and Total Emissivity of High-Temperature. Int. J. Thermophys. 1998, 19, 917-929. [CrossRef]

26. Greene, G.; Finfrock, C.C.; Irvine, T.F. Total hemispherical emissivity of oxidized Inconel 718 in the temperature range $300-1000{ }^{\circ} \mathrm{C}$. Exp. Therm. Fluid Sci. 2000, 22, 145-153. [CrossRef]

27. Encinas-Oropesa, A.; Drew, G.L.; Hardy, M.C.; Leggett, A.J.; Nicholls, J.R.; Simms, N.J. Effects of Oxidation and Hot Corrosion in a Nickel Disc Alloy, in Superalloys 2008. In Proceedings of the Eleventh International Symposium, Champion, PA, USA, 14-18 September 2008; pp. 609-618.

28. Gabb, T.P.; Telesman, J.; Kantzos, P.T.; Smith, J.W.; Browning, P.F. Effects of high temperature exposures on fatigue life of disk superalloys. In Proceedings of the Superalloys 2004, Champion, PA, USA, 19-23 September 2004.

29. Pineau, A. High temperature fatigue of Ni-base superalloys: Microstructral and enviromental effects. In Engineering Against Fatigue; Taylor \& Francis: Sheffield, UK, 1999.

30. Brandt, R.; Bird, C.; Neuer, G. Emissivity reference paints for high temperature applications. Measurement 2008, 41, 731-736. [CrossRef]

31. Bird, C.; Mutton, J.E.; Shepherd, R.; Smith, M.D.W.; Watson, H.M.L. Surface Temperature Measurement in Turbines; Rolls-Royce Plc.: Chichester, UK, 1998.

32. Pelloux, R.M.; Marchand, N. Thermal-Mechanical Fatigue Behavior of Nickel-Base Superalloys; Massachusetts Institute of Technology: Cambridge, MA, USA, 1986.

(C) 2018 by the author. Licensee MDPI, Basel, Switzerland. This article is an open access article distributed under the terms and conditions of the Creative Commons Attribution (CC BY) license (http://creativecommons.org/licenses/by/4.0/). 